UDC 004.896

\title{
MODEL FOR EFFICIENT ALLOCATION OF NETWORK FUNCTIONS IN HYBRID ENVIRONMENT
}

\author{
Mariia A. Skulysh, Larysa S. Globa, Svitlana V. Sulima \\ National Technical University of Ukraine "Kiev Polytechnic Institute”, Kiev, Ukraine
}

Background. To ensure the required quality of experience and optimal use of network operator's resources in the current conditions telecommunication operator can deploy services using the concept of Network Functions Virtualization (NFV), that has fundamental differences from traditional dedicated hardware. To achieve the expected benefits of NFV, physical resources must be used effectively. This requires effective algorithms to determine onto which physical resources network functions are allocated.

Objective. The aim of the paper is to improve the efficiency of mobile network through optimal resource allocation in hybrid data center environment.

Methods. Analysis of all known publications devoted to virtualization of network functions of mobile network has shown the modeling approach to resource allocation and also has shown the absence of decisions on important issues of this process (performance of functional blocks, heterogeneous environment).

Results. An analytical approach to model and investigate the resource allocation of network functions on a telecommunication operator's network is proposed.

Conclusions. To model the resource allocation for virtualized network functions a technique of virtual network embedding can be used, while changing the constraints in which you can get the results for a variety of deployment scenarios. In such way, adding a number of constraints to the classical formulation of the problem, we can take into account the performance of the network functions and heterogeneity (hybridity) of the deployment environment.

Keywords: NFV; cloud computing; resource allocation; virtual network embedding.

\section{Introduction}

A rapid growth can be seen in the mobile cellular communications in recent years, particularly with the introduction of $4 \mathrm{G}$ network LTE. Today's mobile customers desire to remain connected anywhere, at any time, and using any device. This phenomenon has encouraged mobile network operators to build complex network architectures by incorporating new features and extensions, which are harder to manage and operate [1]. Two concepts are in the focus of research and development at the moment - Network Functions Virtualization (NFV) and Software Defined Networking (SDN) [2].

Existing mobile network infrastructures are composed of dedicated network nodes which are typically placed at different points in the network, and each node is assigned a specific set of functions and services to provide. Fig. 1 depicts a typical LTE/EPC architecture which shows network elements like PDN Gateway (PGW), Service Gateway (S-GW), Mobility Management Entity (MME), Policy Charging and Rules Function (PCRF), which are interconnected via well defined interfaces and each network element is assigned a dedicated set of specialized functions/services. In other words, network functions and services are topologically fixed in dedicated network nodes, which are commonly hierarchically organized according to their functions. Such a centralized architecture renders itself inflexible in terms of new-service roll-outs, incurs non-optimum routing of traffic, and inefficient utilization of network resources. Moreover, the scalability and cost-efficiency of such architecture is getting challenging in view of latest traffic forecasts and users' expectations [3].

With the proliferation of powerful mobile devices (e.g., smart phones, tablet PCs, and laptops) and the growing popularity of mobile multimedia applications, an increased demand for bandwidth is expected [3]. According to [4] overall mobile data traffic is expected to grow to 24.3 exabytes per month by 2019 , nearly a tenfold increase over 2014. Mobile data traffic will grow at a CAGR of 57 percent from 2014 to 2019 (Fig. 2).

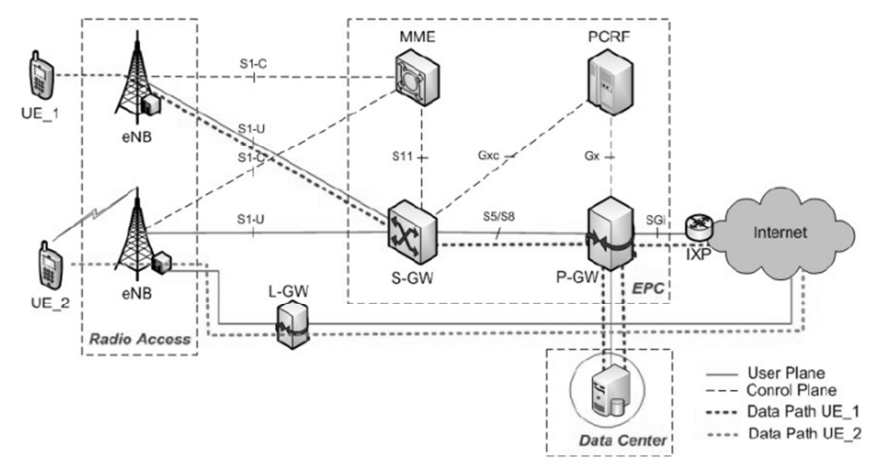

Fig. 1 Generic EPC mobile network infrastructure [3] 


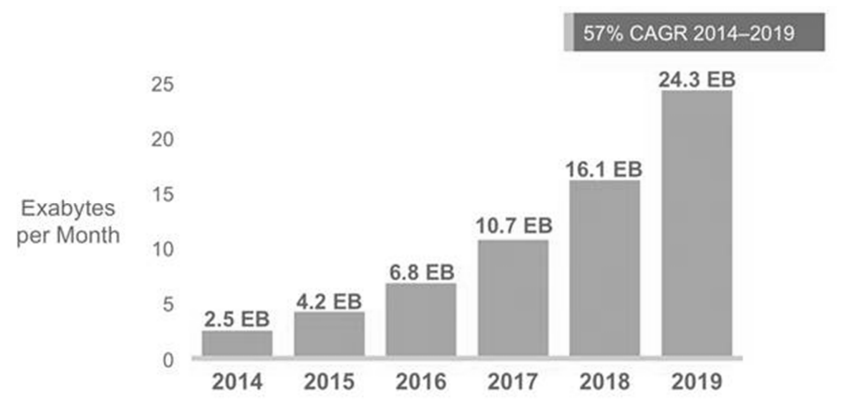

Fig. 2 Cisco forecasts 24.3 exabytes per month of mobile data traffic by 2019 [4]

In addition to the typical eNodeB, S/PGW, MME and other network functions [5], an EPC deployment requires the following functions typically installed in independent boxes: i) Network Address Translation (NAT) from private IPv4 addresses to public IPv4/v6 addresses; ii) service access policing, e.g., for VPN, video platforms and VoIP; iii) infrastructure firewall protection; iv) a content distribution network (CDN) solution for efficient popular content distribution; and v) transcoding engines for optimized picture and video delivery [6]. The substantial dependence of networks on their underlying hardware and the existence of various specialized hardware appliances, such as firewalls, deep packet inspection (DPI) equipment, and routers, in the network infrastructure have escalated the challenges facing network service providers [7].

Typically, mobile network operators dealt with increased traffic loads by extending/upgrading the overall network capacity accordingly. However, this becomes more and more difficult to implement due to increased Capital/Operational Expenditures (CAPEX/OPEX) in the light of the low Return on Investment (ROI). Besides low ROI, resource over-provisioning is no longer considered a viable strategy to cater to increasing traffic, as according to [8] up to $80 \%$ of base stations processing capacity and up to half of core network's capacity is unused. This leads to low network resource utilization and also to high energy consumption, both of which decrease the cost efficiency of the network for mobile network operators [3].

The principle of NFV [9] aims to transform network architectures by implementing network functions in software that can run in industry standard hardware. Furthermore, it aims to transform traditional network operations, as software can easily be moved to, or instantiated in, various locations (e.g. data centers, network nodes, end-user premises) without the need to use new equipment. NFV can bring many benefits, from improving operational efficiency and reducing power usage to shorter deployment/upgrade intervals and near-optimal network resource usage as the building blocks can be allocated and reallocated at runtime depending on demand $[10,11]$.
The possibility of incremental and scalable functional additions without the need to install or acquire specialized equipment is definitely of huge value. Dynamic network instantiation is seen as an important tool to cope with the rapid change of services and users behavior. Therefore, it is expected that NFV would have an impact on the desired cost reduction in today's mobile networks [2].

Meanwhile, SDN [12] has been considered as a complementary deployment concept for mobile networks. SDN introduces what is called Network Functions Decomposition (NFD), where control-plane functions would be appended to a logically centralized controller that could be deployed in a datacenter platform, while data-plane functions are realized by SDN networking elements at the transport network [2].

Different deployment scenarios of SDN and NFV could be envisioned, depending on the network segments (e.g., core or edge) and, consequently, on the time horizon (e.g., medium-long term or short term). Nevertheless this overall trend of network "softwarization" is unstoppable, because of the continuous technology evolution and costs reductions [13].

In practice, the more expensive dedicated hardware often performs faster and more efficiently than virtualized instances, even though the latter are more flexible. As dedicated hardware is currently widely deployed, it is likely that hybrid deployments will be common, where part of the services is provided by physical hardware. This results in a scenario analogous to a cloud burst: a base load is handled by physical hardware (the private cloud in a cloud burst scenario), while variation in load is handled by dynamically instantiating services (the public cloud in a cloud burst scenario). In this "NFV burst" scenario, a base load is handled by physical hardware while spillover is handled by virtual service instances. This approach is illustrated in Fig. 3.

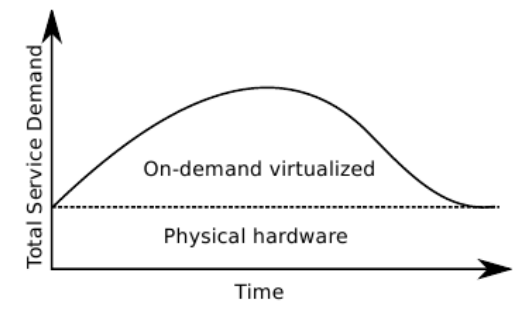

Fig. 3 An NFV burst scenario: physical hardware is fully utilized by a base load, while spillover is handled by utilizing virtualized services [11]

In NFV networks, a collection of service chains must be allocated on physical network nodes. A service chain is a collection of one or more services or virtual machines that are chained together to provide specific functionality, and can be represented as a graph containing services and the network demand between these services. In a hybrid network environment, service chains 
can be allocated either using physical hardware, or by using virtualized instances. These two approaches are illustrated in Fig. 4.

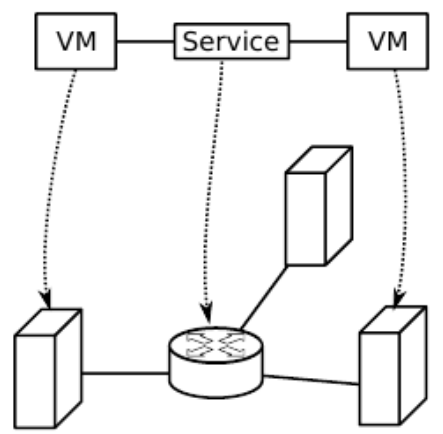

(a) Services can be allocated on physical devices Fig. 4 NFV service chain allocation approaches [11]

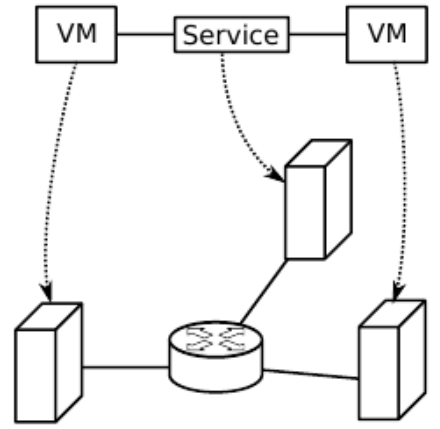

(b) Alternatively, services can be offered using virtualized instances on generic hardware

Fig. 4 NFV service chain allocation approaches [11]

The success of this approach depends on the existence and performance of algorithms that determine where, and how these building blocks are instantiated [11].

The overall service attributes, in particular reliability, availability, manageability, security and performance will depend on the individual (virtualized) network function attributes, as well as how these functions are connected [14].

Although NFV promises significant cost savings, flexibility and ease of deployment, potential challenges in implementing virtualized network elements that can support real-world performance requirements are still an open question [15] and currently NFV is still at the initial implementation stages [16]. The subject of a virtualized EPC that can be dynamically reconfigured is quite new in itself. That is why there is not much work [3].

To achieve the economies of scale expected from NFV, physical resources should be used efficiently. It has been shown that default deployment of some current use cases may result in sub-optimal resource allocation and consumption [17].

This calls for efficient algorithms to determine on to which physical resources (servers) network functions are placed [18].
Allocating resources in NFV networks is similar to application placement in datacenters and clouds [19], specifically to network-aware application placement. Many publications (for example, [20]) focus on either allocating collections of virtual machines, or on adding network-awareness to datacenter resource management algorithms. These works however focus specifically on Infrastructure as a Service (IaaS) clouds where virtual machines are allocated [11].

The task of placing functions is also closely related to virtual network embedding [21]. In the last years, many scientific contributions [22] addressed the virtual network embedding problem, either applying mathematical optimization models (e.g. [2], [11], [23]) or algorithmic approaches (e.g. [24]).

In a general sense, the problem of load-aware EPC configuration can be reduced to graph mapping. The EPC forms a graph of core network functions (S-GW, MME, P-GW, etc.) [3]. Virtual network mapping plays a central role in building a virtual network. During this mapping process each node of the virtual network is assigned to a node of the physical network and each virtual link is assigned to a path or flow in the physical network, such that a set of previously defined constraints (e.g. topology constraints, data rate, CPU capacity) is satisfied.

The main objective in solving the virtual network mapping problem is to make efficient use of the underlying resources, while still satisfying the set of previously defined mapping constraints. In addition, a virtual network mapping problem algorithm should be able to handle dynamically arriving online requests and also offer admission control, since some $\mathrm{VN}$ requests must be rejected or postponed to avoid violation of resource guarantees for already existing virtual networks [24].

For example, the controllers placement problem has been previously addressed in [25] and [26] but with a main focus on achieving minimum SDN control delay as well as resilience provisioning. In the study [2] the optimal virtualized gateways placement is considered as well as the problem of virtualization and SDN decomposition deployment on the mobile core gateways. However, the placement problem also arises for other network functions. Similar to the controller placement problem in the SDN domain, technologies like NFV call for appropriate algorithms that can tackle challenges beyond the single criterion placement problems. These problems might introduce additional complexity due to possible interdependencies between the network functions as in the case of function chaining and potential new constraints regarding additional aspects like security [27].

Although the mapping of virtual network functions is related to virtual network embedding, however, the network functions mapping problem has a third addi- 
tional dimension of network functions on top of the virtual machines [28].

In this article we extend the embedding approach by defining network functions placement model, incorporating the notion of hybrid networks containing both physical devices offering services and virtualized services. Similarly, [11] also focuses on deployment of virtual network functions in a hybrid environment, however it does not consider the fact that the performance of service instance depends on the amount of the allocated resources.

Also important to note is that our work differs from more general strategies for resource management in cloud environments, as the EPC is a graph of interdependent nodes, which cannot be considered in isolation [3].

Therefore, the objective of the study is to improve the efficiency of mobile networks through optimal resource allocation in hybrid data center environment. In this direction, the paper proposes an analytical approach to model and investigate the allocation of network functions on a telecommunication operator's network.

\section{A Model Description}

Our approach relies on the joint embedding of individual core network service chains on a physical substrate network where a core network service chain denotes the sequence of mobile core network functions traffic flow has to traverse. We assume that the mobile core virtual network functions comprise the same functionality and interfaces as the core network elements of the 3GPP LTE Evolved Packet Core (EPC) architecture (Fig. 1).

The physical substrate network is given as a graph $S N=(N, L)$ where $N$ is the set of physical nodes and $L$ is the set of links. Every link $l=\left(n_{1}, n_{2}\right) \in L, n_{1}, n_{2} \in N$ has a maximum capacity $c\left(n_{1}, n_{2}\right)$ and every node $n \in N$ is associated with certain resources $c_{n}{ }^{i}, i \in R$, where $R$ is the set of resource types. The set of all traffic aggregation points (TAPs), i.e. clusters of eNodeBs, in the network is denoted by $T \subseteq N$. For every node $n \in N$, virt $_{n}$ is a binary parameter, which indicates whether the node $n$ is virtual, phys ${ }_{n}{ }^{j}$ is a binary parameter, which indicates whether the node $n$ is dedicated hardware of type $j \in F$, where $F$ is the set of network function types.

The virtual mobile core network is represented by the set of service chains (one chain per TAP) which are embedded onto the physical substrate network.

The bandwidth demand of a link between two functions, $j 1$ and $j 2$, that belongs to the service chain of TAP $t \in T$ is denoted as $d_{t}^{(j 1, j 2)} . d_{t}^{j, i}-$ the amount of resource type $i$, that is allocated for network function $j$ of TAP $t . s_{t}^{j, i}$ denotes the processing time of a request on the resource type $i$ of network function $j$ of TAP $t$ by one unit of resource for the case of virtual network function. Requests per second of dedicated hardware functional module $n$ of type $j$ is given and is denoted as $\mu c_{n}^{j}$. The requests per second requirements of a network function $j$ that belongs to the service chain of TAP $t$ are denoted as $M_{t}^{j}$.

The optimization target is to find an embedding of the core network service chains (i.e. the placement of the core network functions and their resource allocations and also the determination of the traffic paths between them) so as to minimize the cost of the occupied link and node resources in the physical substrate network while accommodating the traffic demand. We formulate the objective function (Equation (1)) as a linear combination (with weight factors $a, b, c$ ) of three cost terms: Basic cost $\operatorname{cost}(n)$ that occurs if any network function is placed on a physical substrate node $n \in N$, cost per occupied resource unit $\operatorname{cost}(i, n)$ on a physical substrate node $n$ and cost per occupied capacity unit $\operatorname{cost}\left(n_{1}, n_{2}\right)$ on a physical link $\left(n_{1}, n_{2}\right) \in L$.

The following Equations (1)-(10) represent the integer nonlinear programming formulation of the optimization problem. The variables $x_{n}^{t, j}$ indicate, if the network function $j$ related to TAP $t \in T$ is located at the physical node $n$. For $j=\mathrm{TAP}$, the $x_{n}^{t, T A P}$ are not variables but input parameters which indicate where the TAP $t \in$ $T$ is located, i.e.

$$
x_{n}{ }^{t, T A P}=\left\{\begin{array}{c}
1 \text { if } t=n, \\
0 \text { else. }
\end{array}\right.
$$

Similarly, the variables $f_{\left(n_{1}, n_{2}\right)} t,\left(j_{1}, j_{2}\right)$ specify, if the physical link $\left(n_{1}, n_{2}\right) \in L$ is used for the path between $j_{1}$ and $j_{2}$ for TAP $t \in T$.

$$
\begin{aligned}
& \min _{x_{n}{ }^{t, j}, f_{\left(n_{1}, n_{2}\right)}{ }^{t,\left(j_{1}, j_{2}\right)}, d_{t}{ }^{j, i}}\left(a \cdot \sum_{n} x_{n} \cdot \cos t(n)+\right. \\
& b \times \times \sum_{n} \sum_{t} \sum_{j} \sum_{i} x_{n}{ }^{t, j} \times d_{t}^{j, i} \times \operatorname{cost}(i, n)+c \times \\
& \times \sum_{\left(n_{1}, n_{2}\right)} \operatorname{cost}\left(n_{1}, n_{2}\right) \times \\
& \left.\times \sum_{t} \sum_{\left(j_{1}, j_{2}\right)} f_{\left(n_{1}, n_{2}\right)}{ }^{t,\left(j_{1}, j_{2}\right)} \cdot d_{t}{ }^{\left(j_{1}, j_{2}\right)}\right) \\
& \sum_{t \in T} \sum_{j \in V} x_{n}{ }^{t, j} \cdot d_{t}^{j, i} \leq c_{n}{ }^{i} \forall n \in N, i \in\{R \backslash \\
& b d w\}(5) \\
& \sum_{t \in T} \sum_{\left(j_{1}, j_{2}\right) \in E} f_{\left(n_{1}, n_{2}\right)}{ }^{t,\left(j_{1}, j_{2}\right)} \cdot d_{t}{ }^{\left(j_{1}, j_{2}\right)} \leq \\
& \leq c\left(n_{1}, n_{2}\right) \quad \forall\left(n_{1}, n_{2}\right) \in L
\end{aligned}
$$




$$
\begin{aligned}
& \sum_{(n, w) \in L} f_{(w, n)}{ }^{t,\left(j_{1}, j_{2}\right)}-f_{(n, w)}{ }^{t,\left(j_{1}, j_{2}\right)}=x_{n}^{t, j_{1}}- \\
& -x_{n}^{t, j_{2}} \forall t \in T, n \in N,\left(j_{1}, j_{2}\right) \in E \\
& x_{n}^{t, j}, f_{\left(n_{1}, n_{2}\right)}^{t,\left(j_{1}, j_{2}\right)} \in\{0,1\} \\
& \forall t \in T, j \in V, n \in N,\left(j_{1}, j_{2}\right) \in E,\left(n_{1}, n_{2}\right) \in L \\
& \mu_{t}^{j} \geq M_{t}^{j} \forall t \in T, j \in V \text {, } \\
& \mu_{t}{ }^{j} \\
& =\sum_{n \in N}\left(x_{n}^{t, j} \cdot \sum_{i \in\{R \backslash b d w\}} \frac{d_{t}^{j, i}}{s_{t}^{j, i}} \cdot \operatorname{virt}_{n}+\right. \\
& \left.+x_{n}{ }^{t, j} \mu c_{n}{ }^{j} \text { phys }_{n}{ }^{j}\right) \quad \forall t \in T, j \in V \\
& \sum_{\left(j_{1}, \dot{j}_{2}\right) \in E} \sum_{\left(n_{1}, n_{2}\right) \in L} f_{\left(n_{1}, n_{2}\right)}{ }^{t,\left(j_{1}, j_{2}\right)} \cdot L\left(n_{1}, n_{2}\right) \leq \\
& \leq L_{t} \forall t \in T \text {, }
\end{aligned}
$$

where $x_{n}{ }^{t, j}$ - variable for the embedding of network function $j$ related to TAP $t$ at the physical node $n$;

$$
\text { - variable for the embedding of link be- }
$$

tween $j_{1}$ and $j_{2}$ for TAP $t$ at the physical link $\left(n_{l}, n_{2}\right)$; $d_{t}^{j, i}$ - amount of resource type $i$, that is allocated for network function $j$ of TAP $t$;

$\operatorname{cost}(n), \operatorname{cost}\left(n_{1}, n_{2}\right)-\operatorname{costs}$ for physical node $n$ and physical link $\left(n_{1}, n_{2}\right) \in L$;

$\operatorname{cost}(i, n)$ - costs for one unit of $i \in R$ at node $n \in N$; $a$ - weight of basic cost term;

$b$ - weight of cost per occupied resource unit term;

$c$ - weight of cost per occupied capacity unit term;

$c_{n}{ }^{i}$ - capacity of resource $i \in R$ of physical node $n \in N$; $c\left(n_{1}, n_{2}\right)$ - bandwidth capacity of physical link $\left(n_{1}, n_{2}\right) \in$ $L$

$d_{t}^{(j 1, j 2)}$ - bandwidth demand for link $(j 1, j 2)$;

$v_{i r t}$ - binary parameter, which indicates whether the node $n$ is virtual;

phys ${ }_{n}{ }^{j}$ - binary parameter, which indicates whether the node $n$ is dedicated hardware of function of type $j$;

$\mu_{t}^{j}-$ requests per second of network function $j$ of TAP $t$

$M_{t}^{j}$ - demanded requests per second value for network function $j$ of TAP $t$;

$\mu c_{n}^{j}-$ requests per second of dedicated hardware functional module $n$ of type $j$;

$L\left(n_{1}, n_{2}\right)$ - the network latency of a link $\left(n_{1}, n_{2}\right) \in L$;

$L_{t}-$ the maximum latency for TAP $t \in T$.

The variables $x_{n}$ are binary indicator variables which denote, whether any network function is placed on node $n \in N$, e.g. $x_{n}=0$ means, that no network function from any service chain is placed at that node.

Equation (2) guarantee, that for every TAP/service chain only one network function of each type is placed. Equation (3) guarantee, that the resource allocation is performed on physical nodes that are chosen to host the respective network functions. The Equations (4), (5) and (6) represent the resource constraints of the physical nodes and links. Note that a link between two network functions is mapped on a path in the physical network. Thus, its bandwidth requirement affects not only the switching resources at the physical nodes where the network functions are placed, but also the switching resources of the intermediate nodes which lie on the path (Equation (4)). Equation (7) represents the flow conservation constraints for all paths (related to links) in the physical network. Equation (8) assures that the decision variables for the network function placement and the path mapping are binary.

To add performance-awareness to the model, a requests per second constraint, expressed in Equation (9) is needed to ensure that the total service rate of network function $j$ of TAP $t$ denoted as $\mu_{t}^{j}$ exceed the demanded value.

To limit the latency on connections, a latency constraint, shown in Equation (10) is also added to limit the total delay over the entire path.

The problem (1)-(10) is assumed to be solved in offline manner on the initial stage. According to the solution each network function module is given a certain amount of resources based on coarse-grain estimates of its resource needs; the instantaneous needs of various network functions are dynamically satisfied at run-time so as to meet the guarantees provided to each network function. The run-time resource allocation is out of scope of the paper.

The modeling of the proposed above method (1)(10) was conducted using MATLAB (Fig. 5), where objective function is Equation 1 and constraint function consists of Equations (2)-(10). A simple modeling example of the system with ten nodes, three network functional blocks and two types of resources showed that compared with the fixed resource allocation the proposed method can perform 3 times better. The change in the total cost while changing the requests per second service demand is illustrated in Fig. 6.

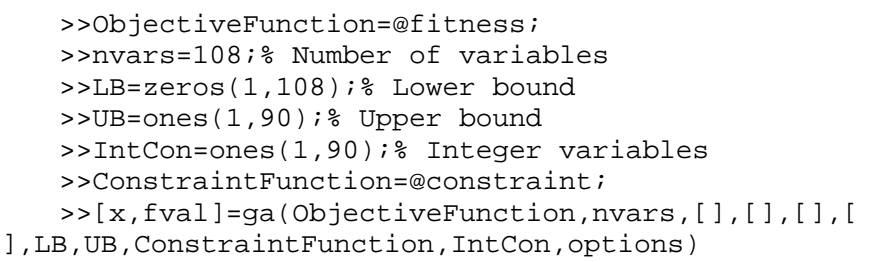

Fig. 5 MATLAB code fragment

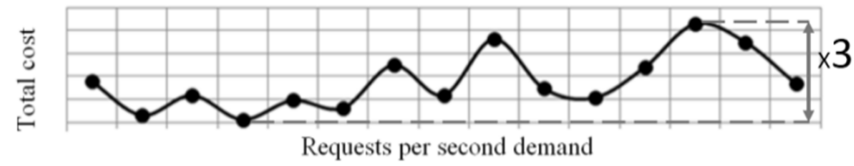

Fig. 6 Total cost while changing requests per second service demand 


\section{Conclusion}

The paper argues that the dynamic provision of resources in virtualized mobile communication systems raises new problems not addressed in previous studies.

The paper considers the mobile network virtualization. Quality of telecommunication networks, based on SDN, SDR, NFV, functioning support task is having significant changes. Specifically, the functioning of telecommunication network software modules is becoming dependent on the power of computing resources on which they are implemented. Quality of service for end users directly depends on the performance of virtual switching nodes. That is why there is a need for mathematical models and methods that ensure optimal resource allocation. Given model can be used in Cloud QoS Control Center [29]. The model can be used in the deployment management of network functions in heterogeneous hardware environment in order to minimize operator costs and improve quality of experience. In this study partial deterioration of some service quality indicators is allowed within acceptable values, allowing for the optimal allocation of resources and economic efficiency of physical resources usage.

In further studies, the proposed model can be extended and incorporated in a complex method of dynamic resource allocation under varying workload conditions.

\section{References}

1. Bradai A. Cellular software defined networking: a framework / A. Bradai, K. Singh, T. Ahmed, T. Rasheed // IEEE Communications Magazine. - 2015. - Vol. 53, No. 6. - pp. 36-43.

2. Basta A. Applying NFV and SDN to LTE mobile core gateways, the functions placement problem / A. Basta, W. Kellerer, M. Hoffmann, H. Morper et al. // 4th workshop on All things cellular: operations, applications, \& challenges. Chicago, USA, 2014.- pp. 33-38.

3. Yousaf F. Z. SoftEPC - Dynamic instantiation of mobile core network entities for efficient resource utilization / F. Z. Yousaf, J. Lessmann, P. Loureiro, S. Schmid // 2013 IEEE International Conference on Communications (ICC). Budapest, Hungary, 2013.- pp. 3602-3606.

4. Cisco Visual Networking Index: Global Mobile Data Traffic Forecast Update 2014-2019 White Paper [Online]. Available http://www.cisco.com/c/en/us/solutions/collateral/serviceprovider/visual-networking-index-vni/white_paper_c11520862.html.

5. Balbas J. Policy and charging control in the evolved packet system / J. Balbas, S. Rommer, J. Stenfelt // IEEE Communications. - 2009. - Vol. 47, No. 2. - pp. 68-74.

6. John W. Research Directions in Network Service Chaining / W. John, K. Pentikousis, G. Agapiou, E. Jacob et al. // 2013 IEEE SDN for Future Networks and Services. Trento, 2013.- pp. 1-7.
7. Hawilo H. NFV: state of the art, challenges, and implementation in next generation mobile networks (vEPC) / $\mathrm{H}$. Hawilo, A. Shami, M. Mirahmadi, R. Asal // IEEE Network. - 2014. - Vol. 28, No. 6. - pp. 18-26.

8. Liquid Core [Online]. - Available at: http://networks.nokia.com/portfolio/liquidnet/liquidcore.

9. Network Function Virtualization [Online]. - Available at: http://portal.etsi.org/NFV/NFV_White_Paper3.pdf.

10. Soares J. Cloud4nfv: A platform for virtual network functions / J. Soares, M. Dias, J. Carapinha, B. Parreira, S. Sargento // 2014 IEEE 3rd International Conference on Cloud Networking (CloudNet). - Luxembourg, 2014. - pp. 288-293.

11. Moens H. VNF-P: A model for efficient placement of virtualized network functions / H. Moens, F. De Turck // 10th International Conference on Network and Service Management. - Rio de Janeiro, 2014. - pp. 418-423.

12. Software-Defined Networking: The New Norm for Networks [Online]. - Available at: https://www.opennetworking.org/downloads/sdnresources/white-papers/wp-sdn-newnorm.pdf.

13. Lombardo A. An analytical tool for performance evaluation of software defined networking services / A. Lombardo, A. Manzalini, V. Riccobene, G. Schembra // 2014 IEEE Network Operations and Management Symposium (NOMS). - Krakow, 2014. - pp. 1-7.

14. Network Functions Virtualisation (NFV); Architectural Framework [Online]. - Available at: http://www.etsi.org/deliver/etsi_gs/nfv/001_099/002/01.01.01 _60/gs_nfv002v010101p.pdf.

15. Rajan A.S. Understanding the bottlenecks in virtualizing cellular core network functions / A.S. Rajan, S. Gobriel, C. Maciocco, K.B. Ramia et al. // 2015 IEEE International Workshop on Local and Metropolitan Area Networks (LANMAN). - Beijing, 2015.- pp. 1-6.

16. Ferrer Riera J. Virtual network function scheduling: Concept and challenges / J. Ferrer Riera, E. Escalona, J. Batalle, E. Grasa, J. A. Garcia-Espin // 2014 International Conference on Smart Communications in Network Technologies (SaCoNeT). - Vilanova i la Geltru, 2014. - pp. 1-5.

17. Veitch P. An instrumentation and analytics framework for optimal and robust NFV deployment / P. Veitch, M. J. McGrath, V. Bayon // IEEE Communications Magazine. 2015. - Vol. 53, No. 2. - pp. 126-133.

18. Mijumbi R. Network Function Virtualization: Stateof-the-art and Research Challenges / R. Mijumbi, J. Serrat, J. Gorricho, N. Bouten et al. // IEEE Communications Surveys \& Tutorials. - 2015. - Vol. PP, No. 99. - pp. 1-28.

19. Jennings B. Resource management in clouds: Survey and research challenges / B Jennings, R Stadler // Journal of Network and Systems Management. - 2014. - pp. 1-53.

20. Alicherry M. Network aware resource allocation in distributed clouds / M. Alicherry, T. Lakshman // 2012 IEEE International Conference on Computer Communications (Infocom 2012). - Orlando, FL, 2012. - pp. 963-971.

21. Fischer A. Virtual Network Embedding: A Survey / A. Fischer, J. Botero, M. Till Beck, H. de Meer and X. Hesselbach // IEEE Communications Surveys \& Tutorials. 2013. - Vol. 15, No. 4. - pp. 1888-1906.

22. Baumgartner A. Mobile core network virtualization: A model for combined virtual core network function placement 
and topology optimization / A. Baumgartner, V.S. Reddy, T. Bauschert // 2015 1st IEEE Conference on Network Softwarization (NetSoft). - London, 2015. - pp. 1-9.

23. Mehraghdam S. Specifying and placing chains of virtual network functions / S. Mehraghdam, M. Keller, H. Karl // 2014 IEEE 3rd International Conference on Cloud Networking (CloudNet). - Luxembourg, 2014. - pp. 7-13.

24. Lischka J. A virtual network mapping algorithm based on subgraph isomorphism detection / J. Lischka, H. Karl // Proceedings of the 1st ACM workshop on Virtualized infrastructure systems and architectures. - 2009. - pp. 81-88.

25. Heller B. The controller placement problem / B. Heller, R. Sherwood, N. McKeown // ACM HotSDN. - Helsinki, Finland, 2012. - pp. 1-6.

26. Hock D. Pareto-optimal resilient controller placement in SDN-based core networks / D. Hock, M. Hartmann,
S. Gebert, M. Jarschel et al. // 25th International Teletraffic Congress (ITC). - Shanghai, 2013. - pp. 1-9.

27. Lange S. Heuristic Approaches to the Controller Placement Problem in Large Scale SDN Networks / S. Lange, S. Gebert, T. Zinner, P. Tran-Gia et al. // IEEE Transactions on Network and Service Management. - 2015. - Vol. 12, No. 1. - pp. 4-17.

28. Mijumbi R. Design and Evaluation of Algorithms for Mapping and Scheduling of Virtual Network Functions / R. Mijumbi, J. Serrat, J.-L. Gorricho, N. Bouten et al. // 2015 1st IEEE Conference on Network Softwarization (NetSoft). London, 2015. - pp. 1-9.

29. Tykhvynskyi V.O. Perspektyvy setei $5 \mathrm{G}$ y trebovanyia k kachestvu ykh obsluzhyvanyia / V. O. Tykhvynskyi, H. S. Bochechka, // Elektrosviaz. - 2014. - No. 11. - pp. 40-43.

Received in final form on May 15, 2016

\section{Л.С. Глоба, М.А. Скулиш, С.В. Суліма.}

Модель ефективного розміщення мережевих функцій в гібридному середовищі

Проблематика. Для забезпечення потрібної якості обслуговування користувачів та оптимального використання ресурсів мережі оператора у сучасних умовах телекомунікаційний оператор може розгортати сервіси за допомогою концепції Віртуалізації Мережевих Функцій (NFV), що має принципові відмінності від традиційного виділеного апаратного забезпечення. Для досягнення очікуваних від NFV переваг, фізичні ресурси повинні використовуватися ефективно. Це вимагає ефективних алгоритмів визначення на які фізичні ресурси розташовуються мережеві функції.

Мета досліджень. Підвищення ефективності роботи мобільної мережі за допомогою оптимального виділення ресурсів у гібридному середовищі дата центрів.

Методика реалізації. Аналіз всіх відомих публікацій, присвячених віртуалізації мережевих функцій мобільної мережі, дав змогу виявити підхід до моделювання виділення ресурсів, а також показав відсутність рішень щодо важливих питань цього процесу (продуктивності функціональних блоків, гетерогенності середовища).

Результати досліджень. Запропоновано аналітичний підхід до моделювання та дослідження виділення ресурсів для віртуалізованих мережевих функцій у мобільній мережі телекомунікаційного оператора.

Висновки. Для моделювання виділення ресурсів для віртуалізованих мережевих функцій може бути використана методика вбудовування віртуальної мережі (Virtual Network Embedding), змінюючи обмеження в якій можна отримувати результати для різних сценаріїв розгортання. Так, додавши ряд обмежень до класичного формулювання задачі, можна врахувати продуктивність мережевих функцій та гетерогенність (гібридність) середовища розгортання.

Ключові слова: NFV; хмарні обчислення; виділення ресурсів; Virtual Network Embedding.

\section{Л.С. Глоба, М.А. Скулиш, С.В. Сулима.}

Модель эффективного размещения сетевых функций в гибридной среде

Проблематика. Для обеспечения требуемого качества обслуживания пользователей и оптимального использования ресурсов сети оператора в современных условиях телекоммуникационный оператор может разворачивать сервисы с помощью концепции Виртуализации Сетевых Функций (NFV), которая имеет принципиальные отличия от традиционного выделенного аппаратного обеспечения. Для достижения ожидаемых от NFV преимуществ, физические ресурсы должны использоваться эффективно. Это требует эффективных алгоритмов определения на какие физические ресурсы располагаются сетевые функции.

Цель исследований. Повышение эффективности работы мобильной сети с помощью оптимального выделения ресурсов в гибридной среде дата центров.

Методика реализации. Анализ всех известных публикаций, посвященных виртуализации сетевых функций мобильной сети, позволил выявить подход к моделированию выделения ресурсов, а также показал отсутствие решений по важным вопросам этого процесса (производительности функциональных блоков, гетерогенности среды).

Результаты исследований. Предложено аналитический подход к моделированию и исследованию выделения ресурсов для виртуализированных сетевых функций в мобильной сети телекоммуникационного оператора.

Выводы. Для моделирования выделения ресурсов для виртуализированных сетевых функций может быть использована методика встраивания виртуальной сети (Virtual Network Embedding), изменяя ограничения в которой можно получать результаты для различных сценариев развертывания. Так, добавив ряд ограничений к классической формулировке задачи, можно учесть производительность сетевых функций и гетерогенность (гибридность) среды развертывания.

Ключевые слова: NFV; облачные вычисления; выделение ресурсов; Virtual Network Embedding. 